\title{
Prevalence and Molecular Detection of Rotavirus in Children in Ramadi City-Iraq
}

\author{
Suha Ali Abd-Al Fattah ${ }^{1}$, Mohamed Abdullah Hamad², Muhammad Qais AL-Ani ${ }^{3}$ \\ ${ }^{1}$ Assistant Professor, Department of Biology Science, AL-Anbar University, ${ }^{2}$ Director of the Center of \\ Biotechnology and Environmental Technology/University of Fallujah, ${ }^{3}$ Professor, Department of Ophthalmology
}

\begin{abstract}
Matter: This is the first study in Al-Anbar governorate with this design aim to the detection of rotavirus group A (ROVA).

Method: A total of (150) stool samples obtained from children $<5$ years with acute gastroenteritis were randomly collected from Maternity and Children at al-Anbar governorate from (1- 9-2019 to 1-2-2020); Rotavirus was detected by rapid test for stool samples and real-time polymerase chain reaction for blood and serum.

Results: Out of total 150 stool sample there were 101(67.3\%), 49(32.6\%) Negative and positive result respectively, from rapid test. The result of RT-PCR from serum \& blood were Thirty-one (31)81.57\% of (38) samples positive for rotavirus \& eight samples were no ct there was Significant value $(0.0016)(0.0075)$ between PCR (blood, serum) test and Rapid test under $\mathrm{p}<0.05$. Based on that RT-PCR was more sensitive $\&$ specific than rapid test.
\end{abstract}

Keyword: Molecular detection, RT-PCR, Rotavirus, children patients.

\section{Introduction}

Rotavirus is transmitted as a result of contamination of the hand with the stool of infected people, and then it reaches the mouth or respiratory system ${ }^{1,2,3,4}$ Rotavirus (RV) infects small intestinal epithelial cells, inducing severe diarrhea in children, resulting in over 500,000 deaths annually. ${ }^{5}$ The virus replicates in the intestinal villi cells ${ }^{6}$ this replication decreases the ability of the intestine to absorb salts and water. ${ }^{7}$ The symptoms often start with fever, nausea, and vomiting, followed by abdominal cramps and frequent watery diarrhea, which may last for 3-8 days. Infected children may also have a cough and runny nose. , $9,10,11,12,13$ Generally, reinfections are common in Rotavirus disease. ${ }^{14}$ Immunity develops with each infection, so subsequent infections are less severe; adults are rarely affected. ${ }^{15}$ Because of the frequency of the virus in the winter season, it was called winter diarrhea before the virus was discovered. ${ }^{16,1,9,17,18,19}$

Rotavirus is the second cause of death in newborns and the cause of more than half of cases of acute diarrhea according to the WHO report ${ }^{20}$ because no specific antiviral therapy is available, effective RV vaccines are crucial to prevent morbidity and mortality. Treatment of RV infection is only possible through fluid and electrolyte replacement, as no specific antiviral therapy is available ${ }^{821}$.

In 2009, WHO recommended the introduction of RVA vaccines into the routine immunization programs, and despite evidence that these vaccines provide good protection against hospitalizations, the acute gastroenteritis morbidity associated to RVA Internationally, oral rotavirus vaccines available (RotaTeq and Rotarix) ${ }^{22}$ Rotarix (RV1 product from one strain G1P [8] strain is used as a human vaccine in two doses, RotaTeq (RV5) resulting from combining five strains (G1, G2, G3, G4, and G1P[8])., is used as a vaccine in three doses ${ }^{23}$ Early diagnosis of Rotavirus gastroenteritis in hospitalized patients will decline the morbidity and mortality impressively and avoids keeps away from improper utilization of anti-toxins in pediatric patients. ${ }^{14}$ Rotavirus infection is not routinely 
diagnosed in Al-Ramadi hospitals probably due to the cost of its diagnosis and because the clinical spectrum of signs and symptoms are similar to other gastroenteritis infections ${ }^{24,25}$. There is a need for regular detection of RV strains because this information is needed to interpret the results of vaccine studies and epidemiologic surveillance ${ }^{9}$.

This is the first study in Al-Anbar governorate with this design aim to the detection of rotavirus group A (ROVA) \& evaluation methods of detection, initially with a rapid test (immunochromatography) for rotavirus in stool specimen, secondly, by molecular methods RT-PCR. In the other side, we were finding out the epidemiology of rotavirus in AL- Ramadi city in AlAnbar governorate.

\section{Method}

Stool samples were collected from children aged less than 5 years, admitted with acute gastroenteritis to hospitals or outpatient wards, a total of (150)stool samples obtained From (1- 9-2019 to 1-2-2020), from children $<5$ years with acute gastroenteritis were randomly collected from Maternity and Children at alAnbar governorate.

Detection of Rota Virus by Rapid Chromatographic Immunoassay, The chromatographic immunoassay performed to the first method that we used to detect the rotavirus in stool samples according to (Qingdao High top Biotech Co.Ltd, China).

We were extracted RNA of 38 samples (serum \& blood) according to manufactured company (VIASURE RNA -DNA Extraction Kit) protocol Spain.

Samples were stored in clean Eppendorf tub at deep freeze; kit of extraction was stored at room temperature RT $\left(15-30^{\circ} \mathrm{C}\right)$ until the day of the experiment, any lyophilized or dissolved substance must be stored at $-20^{\circ} \mathrm{C}$ (like carrier RNA, Proteinase K) and wash buffer at RT.

After preparing our samples, kits and devices; there were initial steps before isolation RNA according (manufactured company (VIASURE RNA -DNA Extraction Kit) protocol Spain.):

Isolation genomic RNA of rotavirus from serum blood samples according (manufactured company (VIASURE RNA -DNA Extraction Kit) protocol Spain.):
Real-time PCR detection of Rotavirus according (The protocol of DNA \& RNA RT-PCR kit by VIASURE Company - Spin)

Statistical Analysis: All results were conducting statistically on SPSS Ver.22. Frequency distribution and percentage for selected variables were done first. ${ }^{26}$ For all statistical analyses, sig. represent P (Probability) value in every table, a $\mathrm{P}$ value of less than 0.05 was considered statistically significant. For comparison between variables, we used the Pearson Correlation Coefficient, which ranges $(-1$ to +1$)$; a positive value means direct correlation $\&$ negative value means reverse correlation. \& we used Chi-square to compare between the variable. Sensitivity \& Specificity were done by MedCalc® v19.5.2.

\section{Results and Discussion}

Description of the study sample: Rotavirus is still the main cause of diarrhea in children. The World Health Organization has indicated that more than half a million children under the age of five face death as a result of contracting rotavirus, and most of them are from poor countries. ${ }^{27}$

The study included 150 samples from children less than 5 years which suffering from diarrhea, the results were $101(67.3 \%), 49(32.6 \%)$ Negative and positive result respectively, in the rapid test in the stool. The study samples- amounting (150) samples suffering from diarrhea-were collected in the laboratories of the Maternity and Children Hospital in the city of Ramadi, in Anbar governorate, for the period from 1- 9-2019 to 1-2-2020. Samples were rapid test \& RT-PCR.

The present study aims to evaluate detection methods of rotavirus; to contribute as much as possible to the use of the fastest and most accurate method for early detection of the virus, and to provide the necessary treatment to save the lives of children in Iraq, specifically in Anbar Governorate.

\section{Rapid test Results:}

Prevalence \& Influence of Age: The study showed that out of 150 fecal samples, 49 of them infected children (ROV+ positive) with ratio of $32.6 \%$ and the other 101 samples were healthy (ROV- negative) with a ratio of $67.3 \%$. The table 1 also shows that there was no significant statistical difference when comparing the means of age between positive and negative sample 
at $p<0.05$. Table 1: The percentage of the number of children infected with rotavirus compared to the age Mean.

Table 1: The percentage of the number of children infected with rotavirus compared to the age Mean.

\begin{tabular}{|l|c|c|c|c|c|}
\hline Variable & $\begin{array}{c}\text { Rapid } \\
\text { test }\end{array}$ & No. & $\begin{array}{c}\text { Per } \\
\text { cent }\end{array}$ & Mean \pm SD & Sig. \\
\hline \multirow{2}{*}{ Age } & ROV+ & 49 & $32.6 \% *$ & $11.286 \pm 7.5360$ & \multirow{2}{*}{.992} \\
\cline { 2 - 6 } & ROV- & 101 & $67.3 \%$ & $11.267 \pm 12.557$ & \\
\hline
\end{tabular}

This result corresponds to a study conducted in 2018 Ramadi $(32 \%)^{28}$ study in Baghdad showed that thirtythree per cent of all collected samples have positive Rotavirus ${ }^{29}$. and prevalence of $32.2 \%$ in Kaduna State, Nigeria. ${ }^{9}$ with a median of $30 \%$ in Saudi Arabia ${ }^{30}$. And $30.3 \%$ in Baghdad (2018) ${ }^{31}$ In Jordan, Rotavirus was detected in $35 \%$ of children hospitalized with acute gastroenteritis ${ }^{32}$. 39\% in 2012 in Anbar ${ }^{33} .33 \%$ in Baghdad(2016). ${ }^{34}$ But not corresponds to a study in AlDiwaniyah, 2019 there results recorded the incidence of $40 \% .{ }^{35} 42.45 \%$ in the region of Mid Iraq. ${ }^{36}$ In Thi-Qar $201945 \% .{ }^{37}$ (45.2\%) in Taiz. ${ }^{38}$ In Babylon city is $48 \%$.

${ }^{33}$ The reason for the presence of Rotavirus infection in Iraq and neighboring countries despite the use of the vaccine is the emergence of new genotypes and new strains not included in the vaccine, and this is due to the nature of the genome virus of re-assortment ${ }^{39}$ while in Ethiopia $20.4 \%$ for rotavirus infection ${ }^{40} \mathrm{RV}$-associated diarrhea of $25.6 \%$, Brazil ${ }^{41}$.

Influence of Age group: Table 2 shows that the number of infected children within the age group 1-12 months is 35 children, at a rate of $71.4 \%$; the table also shows 12 infected children in age group of 13- 24 months by $24.4 \%$ percent and 2 children at rate of 4 in the 25-60 months out of a total of 49 children. We were found that the stag less than a year was the highest average of infection.

Table 2: percentage of children infected with rotavirus, depending on age group

\begin{tabular}{|l|c|c|}
\hline Age stages & No. & \% \\
\hline $1-12 \mathrm{~m}^{*}$ & 35 & 71.4 \\
\hline $13-24 \mathrm{~m}$ & 12 & 24.4 \\
\hline $25-60 \mathrm{~m}$ & 2 & 4 \\
\hline Total & $\mathbf{4 9}$ & $\mathbf{1 0 0}$ \\
\hline
\end{tabular}

*: Month

This results agreement with ${ }^{38}$ Another study, in Ramadi City, $\operatorname{Iraq}^{28}$. Babylon City study ${ }^{33}$ and with the study. ${ }^{42}$ Group of 7-12 months. ${ }^{31}$ others ${ }^{29}$ Disagree with the study showed that half of the children were below 6 months of age, $37 \%$ in the age group of 7-12 months. ${ }^{10}$ Another study. ${ }^{43}$ The occurrence of rotavirus diarrhea in this age group is probably due to the absence of breastfeeding ${ }^{11}$.

RT-PCR results: The limitation of antibodybased tests for the detection of enteric pathogens is the requirement of high concentration of free antigen to generate a positive reaction; the free antigen is decreased significantly during disease. Therefore, these tests have lower sensitivity and could miss positive samples collected late in the course of clinical disease, when compared to RT-PCR ${ }^{44,45}$.

Thirty-eight (38) samples (21) serum samples \& (17) blood samples were detection for RT-PCR after extraction their RNA in the Biotechnology and Environmental Centre University of Fallujah. Thirtyone (31) of (38) samples were positive for rotavirus \& eight samples were no ct. As in Table 3

Table 3: The result of RT-PCR from serum \& blood.

\begin{tabular}{|l|c|c|c|c|c|}
\hline Type of samples & Positive & \% & No ct & Total & 21 \\
\hline Serum & 14 & $66.66 \%$ & 7 & $33.33 \%$ & $0.0 \%$ \\
\hline Blood & 17 & $100 \%$ & 0 & ------ & 17 \\
\hline Total & 31 & $81.57 \%$ & ------- & 38 \\
\hline
\end{tabular}

Our study showed that (81.57\%) positive for RV which consistent with study showed that $80.6 \%$ among children $<5$ years in Diyala province. ${ }^{3}$ and with $(93.8 \%)$ of positive for RV antigen detected by conventional RTPCR in Diyala, Iraq ${ }^{26}$, with the study ${ }^{39}$ And with study which detects rotavirus from NSP3 gene ${ }^{46}$. 
In addition to positive control which it was reading (26.01) in the FAM filter \& (24.9) in HEX (JOE) filter. The results of samples were reading in the same two filters (according to the protocol of manufactured company).

In the present study we counted on $\mathrm{Ct}$ value $<40$ according protocol of manufactured company of kit to detection positive results corresponding with ${ }^{39}$.
In Figure 1 Carves of amplification were explaining the number of the cycle in (X-axes) vs. intensity in (Y-axes). Fluorescence data (FAM) collection during $60 \mathrm{C}^{\circ}$ extension for rotavirus, their curves higher the threshold line were positive results and the negative result the curves under threshold line in RT- PCR for rotavirus detection ${ }^{47}$.

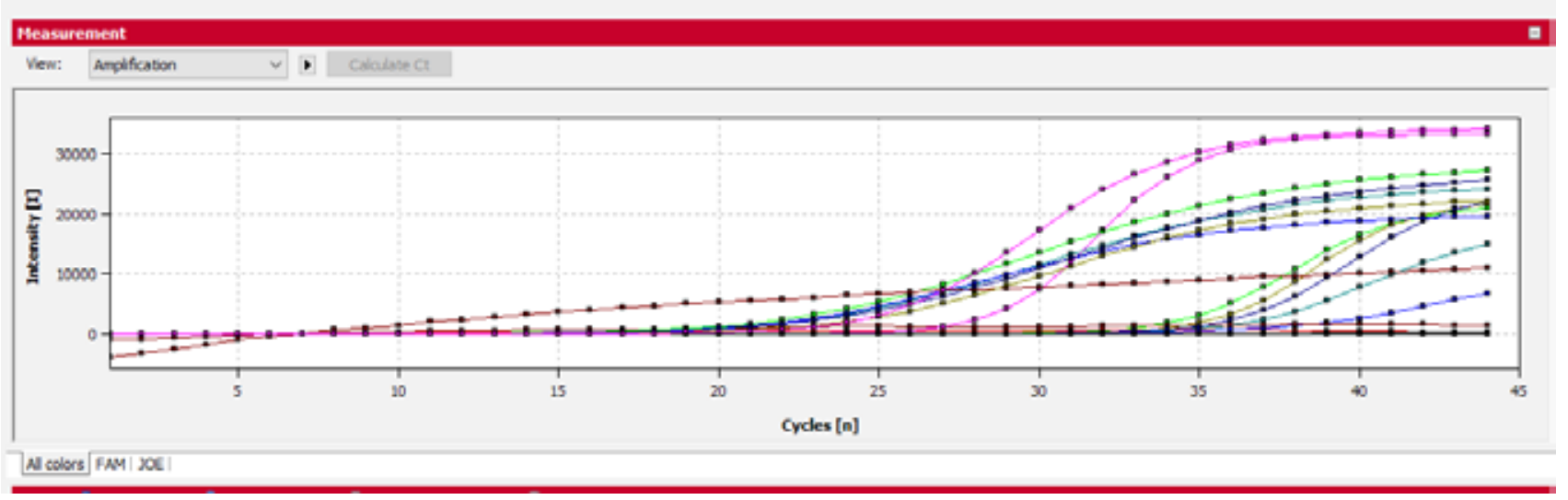

Figure 1: RT-PCR threshold curves for the amplification of NSP3genes of Rotavirus.

Sensitivity \& Specificity: Our study showed (Table 4) that from 14 stool samples, there were 12 true positive (TP) samples and 2 fales negative (FN) samples as a result of rapid test .while for same 14 samples, all their serum in the RT- PCR test were positive and there is no result of false positive (FP), nor a true negative (TN).

Table 4: Compared results between RT-PCR (serum samples) and rapid test (stool samples).

\begin{tabular}{|l|l|c|c|c|}
\hline \multicolumn{2}{|c|}{} & \multicolumn{2}{|c|}{ PCR serum test } & \multirow{2}{*}{ Total } \\
\cline { 3 - 5 } \multicolumn{2}{|c|}{} & + & - & 12 \\
\hline \multirow{3}{*}{ Rapid test } & Count & $12 \mathrm{TP}$ & $0 \mathrm{FP}$ & $100 \%$ \\
& $\%$ Within rapid test + & $85.7 \%$ & $.00 \%$ & 2 \\
& Count & $2 \mathrm{FN}$ & $0 \mathrm{TN}$ & $100 \%$ \\
\hline \multirow{2}{*}{ Total } & $14.2 \%$ & $.00 \%$ & 14 \\
& $\%$ Within rapid test & 14 & 0 & $100 \%$ \\
\hline
\end{tabular}

The sensitivity of PCR serum test $=\mathrm{TP} / \mathrm{TP}+\mathrm{FN} * 100 \rightarrow 12 / 14 * 100=85.7 \%$

Specificity of PCR serum test $=\mathrm{TN} / \mathrm{FP}+\mathrm{TN} * 100 \rightarrow 0 / 0 * 100=$ no specificity

Result of Chi-squared between RT-PCR (serum samples) test and rapid test was (7.143) at DF (1) and there was Significant value (0.0075) under $\mathrm{p}<0.05$.

In the present study (Table 5) that from 17 stool samples, there were 15 true positive (TP) samples and
2 fales negative (FN) samples as a result of rapid test while for same 17 samples, all their samples in the RTPCR test were positive and there is no result of false positive (FP), nor a true negative (TN). 
Table 5: Compared result between RT-PCR (blood samples) test and rapid test

\begin{tabular}{|l|l|l|l|l|}
\hline \multicolumn{2}{|c|}{} & \multicolumn{2}{|l|}{ PCR blood test } & \multirow{2}{*}{ Total } \\
\cline { 3 - 5 } \multicolumn{2}{|c|}{} & + & - & \\
\hline \multirow{4}{*}{ Rapid test } & Count & $15 \mathrm{TP}$ & $0 \mathrm{FP}$ & 15 \\
& \%Within rapid test + & $88.2 \%$ & $0.00 \%$ & $100 \%$ \\
\cline { 2 - 5 } & Count & $2 \mathrm{FN}$ & $0 \mathrm{TN}$ & 2 \\
& \%Within rapid test__ & $11.8 \%$ & $0.00 \%$ & $100 \%$ \\
\hline \multirow{2}{*}{ Total } & 17 & 0 & 17 \\
& $100 \%$ & $100 \%$ & $100 \%$ \\
\hline
\end{tabular}

The sensitivity of PCR blood test $=\mathrm{TP} / \mathrm{TP}+\mathrm{FN} * 100 \rightarrow 15 / 17 * 100=88.2 \%$

Specificity of rapid test $=\mathrm{TN} / \mathrm{FP}+\mathrm{TN} * 100 \rightarrow 0 / 0 * 100=0 \%$ no Specificity

Result of Chi-squared was (9.941) at DF (1) and there was Significant value $(0.0016)$ between PCR blood test and Rapid test under $\mathrm{p}<0.05$.

In our study showed that sensitivity and specificity of PCR serum samples were $85.7 \%$ and no specificity, respectively than Rapid test, sensitivity and specificity of PCR blood samples were $88.2 \%$ and no specificity, respectively than Rapid test, based on that RT-PCR was more sensitive $\&$ specific than rapid test.

RT- PCR has replaced the conventional methods since; they are rapid, accurate and also having good sensitivity and specificity 14 .

\section{Conclusion:}

- Rotavirus continues to threaten the lives of nearly one third of children in Ramadi city.

- Children under one year of age are more likely to be infected with rotavirus, especially males.

- There was correlation between RT-PCR test and rapid test.

- $\quad$ RT-PCR more sensitive than Rapid test.

Conflict of Interests: The authors of this paper declare that he has no financial or personal relationships with individuals or organizations that would unacceptably bias the content of this paper and therefore declare that there is no conflict of interests.

Source of Funding: The authors have no sources of funding, so it is self-funding research.

\section{Conflict of Interest: None}

Ethical Approve: We declare that the study does not need ethical approval.

\section{References}

1. Moyo -PhD thesis S. 9LUDOGLDUUKRHDLQFKLOGUHQXQGHUWZR HDUVRIDJHLQ'DUHV6DODDP7DQ]DQLD provided the funding for the work.

2. Adnan Abdul-Ridha PN, Abdul-Razak Sh Hasan P, lecturer Ansam Salman AD. A comparison study between Enzyme-linked immunosorbant assay and rapid latex agglutination test for the diagnosis of Rotavirus in human. 2015;11(1).

3. Sh Hasan Abbas Al-Duliami A-RA, Abdul-Kadir Y Al-Azawi MS. The Prevalence of Rotavirus Infection in Baquba-Diyala Province. 2011.

4. Shaheen M. Molecular Characterization of Rotavirus Strains Causing Gastroenteritis in Children under 5 Years in Cairo, Egypt. MOJ Public Heal. 2017;6(5):428-32.

5. Uchiyama R, Chassaing B, Zhang B, Gewirtz AT. MyD88-mediated TLR signaling protects against acute rotavirus infection while inflammasome cytokines direct $\mathrm{Ab}$ response. Innate Immun. 2015;21(4):416-28.

6. Morelli M, Ogden KM, Patton JT. Silencing the alarms: Innate immune antagonism by rotavirus NSP1 and VP3. Vols. 479-480, Virology. Academic Press Inc.; 2015. p. 75-84.

7. Abd AA, Al-Nasrawi A. Rotavirus gastroenteritis prevalence among children under five years of age in Karbala City. Vol. 9, Journal of Kerbala University. 2011.

8. Shao L. Rotavirus pathogenesis, innate immunity and their immune modulation by probiotics in a piglet model and in vitro. ProQuest Diss Theses [Internet]. 2015;248. Available from: 
https://search.proquest.com/docview/18307733 94 ? accountid=26646\%0Ahttp://link.periodicos. capes.gov.br/sfxlc141?url_ver=Z39.88-2004 \& rft_val_fmt=info:ofi/fmt:kev:mtx:dissertation \& genre $=$ dissertations $+\% 26+$ theses $\&$ sid $=$ ProQ:Pro Quest+Dissertations+\%26+Theses + Globa

9. Mohammed AA, Aminu M, Ado SA, Jatau ED, Esona MD. Prevalence of rotavirus among children under five years of age with diarrhea in Kaduna State, Nigeria. Niger J Paediatr. 2016;43(4):264.

10. Al-sonboli NN, Mohnna MA Bin. Genotypes of Rotavirus among Yemeni Children with Acute Diarrhea. 2020;(January).

11. Alani1 QA, Ai-Rawi SA, Salih AK, Al-Mawla SOG. Common Rota Virus Gastroenteritis in Children under 5 Years in Maternity and Children Teaching Hospital, western Iraq. Vol. 10, Anb Med J. 2012.

12. Hagbom M. Rotavirus Disease Mechanisms Diarrhea, Vomiting and Inflammation: How and Why. Rotavirus Dis Mech Diarrhea, Vomiting Inflamm How Why. 2015;

13. Hegazi MA, Sayed MH, Sindi HH, Bekhit OE, ElDeek BS, Alshoudri FMY, et al. Is rotavirus still a major cause for diarrheal illness in hospitalized pediatric patients after rotavirus vaccine introduction in the Saudi national immunization program? Med (United States). 2017;96(15).

14. Mythily N, Joe EA, Dhanasekaran A. CERTIFICATE.

15. Beards G. Rotavirus. 2017;4(1):0-2.

16. Sadiq A, Bokhari H, Noreen Z, Asghar RM, Bostan N. Magnitude of Rotavirus A and Campylobacter jejuni infections in children with diarrhea in Twin cities of Rawalpindi and Islamabad, Pakistan. 2019;1-10.

17. Fenjan M, Jarullah B. Molecular Identification And Phylogenetic Analysis Of Rotavirus In Children Suffered From Diarrhea Under Five Years Old In Thi-Qar Provience, Of Iraq. J Coll Educ Pure Sci. 2019;9(1):82-91.

18. Atalay MA. Frequency of Rotavirus infection in children with gastroenteritis in a tertiary hospital. Dicle Med Journal/Dicle Tip Derg. 2013;40(2):2125.

19. Maternity A-R, Hospital C, RAl-Ani ZM, Dch C. Rotavirus in gastroenteritis of infants and children under three years of age hospitalized in.
20. Qadir K. Healthcare providers' knowledge on rotavirus vaccine at selected primary healthcare centers in Erbil City. Zanco J Med Sci. 2016 Sep 1;20(2):1304-9.

21. Getachew HB, Dahl RM, Lopman BA, Parashar UD. Rotavirus Vaccines and Health Care Utilization for Diarrhea in US Children, 2001 to 2015. Pediatr Infect Dis J. 2018;37(9):943-8.

22. Burnett E, Tate JE, Kirkwood CD, Nelson EAS, Santosham M, Steele AD, et al. Estimated impact of rotavirus vaccine on hospitalizations and deaths from rotavirus diarrhea among children $<5$ in Asia. Expert Rev Vaccines. 2018;17(5):453-60.

23. Karafillakis E, Hassounah S, Atchison C. Effectiveness and impact of rotavirus vaccines in Europe, 2006-2014. Vaccine [Internet]. 2015;33(18):2097107. Available from: http://dx.doi.org/10.1016/j. vaccine.2015.03.016

24. Fumian TM, Leite JPG, Rocha MS, de Andrade JSR, Fioretti JM, de Assis RMS, et al. Performance of a one-step quantitative duplex RT-PCR for detection of rotavirus A and noroviruses GII during two periods of high viral circulation. J Virol Method [Internet]. 2016;228:123-9. Available from: http://dx.doi.org/10.1016/j.jviromet.2015.11.008

25. Aliabadi N, Antoni S, Mwenda JM, Weldegebriel G, Biey JNM, Cheikh D, et al. Global impact of rotavirus vaccine introduction on rotavirus hospitalisations among children under 5 years of age, 200816: findings from the Global Rotavirus Surveillance Network. Lancet Glob Heal. 2019;7(7):e893-903.

26. Salman AD. Prevalence of Rota Virus Detection by Reverse TranscriptasePolymerase Chain Reaction in Stool from Children Fewer Than Five Age With Acute Diarrhea in Diyala Province in Iraq. IOSR J Pharm Biol Sci. 2017;12(01):94-9.

27. Al-Shuwaikh AM, Ibrahim IA, Al-Shwaikh RM. Detection of E. coli and Rotavirus in Diarrhea among Children Under Five Years Old. Iraqi J Biotechnol. 2015;14(1):85-92.

28. Muneam A. Incidence of Rota Virus Gastroenteritis among Vaccinated and Non-vaccinated Children Less Than Two Years Old in Ramadi City, Iraq. AlAnbar Med J. 2020;16(1):8-11.

29. Saleem Abdulridha A. Study the effects of age and gender of children on rotavirus infection in Baghdad, Iraq Study the Effects of Age and Gender of Children on Rotavirus Infection in Baghdad, Iraq. 
View project microbiology View project [Internet]. Available from: https://www.researchgate.net/publication $/ 309528008$

30. Kheyami AM, Cunliffe NA, Hart AC. Rotavirus infection in Saudi Arabia. Ann Saudi Med. 2006;26(3):184-91.

31. Hussein SSM, Fadhil SA, Salman RY. Efficacy of Rotavirus Vaccination in Prevention of Hospital Admission of Gastroenteritis among Children Under Two Years of Age. 2018;17(3):225-32.

32. Salem K, Bdour S, Zeller M, Van Ranst M, Matthijnssens J. Genotypes of rotavirus strains circulating in Amman, Jordan, in 2006/07 and their significance for the potential effectiveness of future rotavirus vaccination. Arch Virol. 2011 Sep;156(9):154350 .

33. Mutlak QM, Abdulridha MK, Al- LMA. Updates in the Prevalence of Rotavirus Gastroenteritis in Babylon City. Al Mustansiriyah J Pharm Sci. 2018;18(2):1-12.

34. Abdulridha AS, Abdulridha AS. Effects of age and gender on Rotavirus infection among children in Iraq. Res J Pharm Biol Chem Sci [Internet]. 2016;7(4):700-4. Available from: https://www.researchgate.net/publication/305479001

35. Al-saidy AAS. Role of rotavirus as the cause of acute pediatric diarrhea in Al-Diwaniyah, 2019;18:1-4.

36. Abood WS, Al-Juboury SA, Al-Rodhan MA. Prevalence and factors associated with rotavirus infection among infants admitted for diarrhea in the region of Mid Iraq. Vol. 10, Qadisiya Medical Journal. 2014.

37. Names A. The effect of age, gender, type of feeding and receiving a treatment on the distribution of Enterovirus infection among children in Al- Diwaniyah city, Iraq. 2020;(25):7-17.

38. Al-Badani A, Al-Areqi L, Majily A, AL-Sallami S, AL-Madhagi A, Amood AL-Kamarany M. Rotavirus Diarrhea among Children in Taiz, Yemen: Prevalence-Risk Factors and Detection of Genotypes . Int J Pediatr. 2014;2014:1-9.

39. Al-nasrawy LM, Al-yasseen AKN. Molecular characterization of Rotavirus infection among children with acute gastroenteritis in Al-Najaf AL-Ashraf. 2020;13(2):2-6.
40. Feleke H, Medhin G, Abebe A, Beyene B, Kloos $\mathrm{H}$, Asrat D. Enteric pathogens and associated risk factors among under-five children with and without diarrhea in Wegera district, northwestern Ethiopia. Pan Afr Med J. 2018;29.

41. Luciane Aparecida Pereira A, Mara Raboni S, Nogueira MB, Vidal LR, Monteiro de Almeida S, Debur MC, et al. Rotavirus infection in a tertiary hospital: laboratory diagnosis and impact of immunization on pediatric hospitalization. 2011.

42. Ahmed MLCB, Weddih A, Benhafid M, Bollahi MA, Sidatt M, Makhalla K, et al. Hospitalizations and deaths associated with diarrhea and respiratory diseases among children aged $0-5$ years in a referral hospital of Mauritania. Trop Med Infect Dis. 2018;3(3):0-8.

43. Vrdoljak M, Guzvinec M, Trkulja V, Butic I, Ivic I, Krzelj V, et al. Title: Distribution of Rotavirus Genotypes in Three Croatian Regions Among Children $\square 5$ Years. 2012.

44. Soltan MA, Tsai YL, Lee PYA, Tsai CF, Chang HFG, Wang HTT, et al. Comparison of electron microscopy, ELISA, real time RT-PCR and insulated isothermal RT-PCR for the detection of Rotavirus group A (RVA) in feces of different animal species. J Virol Method. 2016 Sep 1;235:99-104.

45. Soltan MA, Tsai YL, Lee PYA, Tsai CF, Chang HFG, Wang HTT, et al. Comparison of electron microscopy, ELISA, real time RT-PCR and insulated isothermal RT-PCR for the detection of Rotavirus group A (RVA) in feces of different animal species. J Virol Method [Internet]. 2016;235:99104. Available from: http://dx.doi.org/10.1016/j. jviromet.2016.05.006

46. De La Cruz Hernández SI, Anaya Molina Y, Gómez Santiago F, Terán Vega HL, Monroy Leyva E, Méndez Pérez H, et al. Real-time RT-PCR, a necessary tool to support the diagnosis and surveillance of rotavirus in Mexico. Diagn Microbiol Infect Dis. 2018 Apr 1;90(4):272-6.

47. Jabbar Yasir S. Diagnostic Study on NSP5 of Human Rotavirus in Najaf Governorate. Vol. 5, KUFA JOURNAL FOR NURSING SCIENCES. 2015. 